\title{
Author Correction: Surface-engineered sponges for recovery of crude oil microdroplets from wastewater
}

Pavani Cherukupally (iD, Wei Sun, Annabelle P. Y. Wong (iD, Daryl R. Williams, Geoffrey A. Ozin (iD, Amy M. Bilton (D) and

Chul B. Park (D)

Correction to: Nature Sustainability https://doi.org/10.1038/s41893-019-0446-4, published online 16 December 2019.

In the version of this Article originally published, the Author contributions section was incorrect and should have been as follows: 'P.C. designed an interdisciplinary research plan and coordinated the project. P.C., W.S., D.R.W., G.A.O. and C.B.P. designed and analysed materials, P.C. and D.R.W. designed and analysed chemical processes, P.C. and A.M.B. designed and analysed water quality studies. P.C., W.S. and A.P.Y.W. performed experiments. P.C. drafted the manuscript. A.M.B. and C.B.P. edited the manuscript. All authors critically reviewed and approved the final manuscript'.

Additionally, the following sentence was mistakenly omitted from the Acknowledgements section: 'We thank S. Shah and R. Pini for providing access to the X-ray microCT instrument and image analysis, and J. P. M. Trusler for the tensiometer at the Chemical Engineering Department, Imperial College London'.

These sections have now been corrected.

Published online: 13 January 2020

https://doi.org/10.1038/s41893-020-0472-2

(c) The Author(s), under exclusive licence to Springer Nature Limited 2020 